\title{
Fatigue life prediction of 5083 and 5A06 aluminum alloy T-welded joints based on the fatigue characteristics domain
}

\author{
Li Zou, Xinhua Yang
}

Dalian Key Laboratory of Welded Structures and Its Intelligent Manufacturing Technology (IMT) of Rail Transportation

Equipment, Dalian Jiaotong University, China; Sicbuan Provincial Key Lab of Process Equipment and Control, China

Lizon@djtu.edu.cn,yangxbdl@foxmail.com

Jianrong Tan

Department of mechanical engineering and automation, Zhejiang University, China

tij@cad.rju.edu.cn

Hongji Xu, Yibo Sun

Dalian Key Laboratory of Welded Structures and Its Intelligent Manufacturing Technology (IMT) of Rail Transportation Equipment, Dalian Jiaotong University, China

xubongi@@djtu.edu.cn,yibo_sun@126.com

ABSTRACT. Three-point bending fatigue test of 5083 and 5A06 aluminum alloy $\mathrm{T}$-welded joints is carried out, and the fatigue life of the specimens with different influencing factors are obtained. Finite element model of the Twelded joint is established and the nodal force based structural stress is calculated. Neighborhood rough set theory is used for analysis of the factors which influence the fatigue life of the aluminum alloy welded joints. Key influencing factors are studied and the fatigue characteristic domains are determined. The master S-N curve characterized by the nodal force based structural stress range and cycles to failure on bi-logarithmic coordinate as well as S-N curves corresponding to the fatigue characteristic domain are fitted. A case study of fatigue life prediction of 5A06 aluminum alloy welded joint indicates the effectiveness of the fatigue life prediction method based on the fatigue characteristic domain.

KEYwORDs. Fatigue life; Welded joints; Fatigue characteristic domain.

\section{INTRODUCTION}

$\mathrm{M}$ aster S-N curve method, also called equivalent structural stress method or nodal force based structural stress method is a new type of fatigue life prediction technology for welded structures proposed by Dong etc. [1, 2] at the beginning of this century. The structural stress calculated in the master S-N curve method is mesh- 
insensitive, so it is intrinsic to a given joint geometry and loading mode [3]. Due to the mesh-insensitive structural stress calculation, its high precision and widely applicability, the master S-N curve method is one of the most attractive fatigue analysis engineering technologies for welded structures in the world. For example, master S-N curve in ASME code is used for life evaluation for plane steel gate [4]. Hong and Cox [5] proposed a procedure for fatigue behavior of welded joints with multi-axial stress states by using an effective equivalent structural stress range parameter combined normal and in-plane shear equivalent structural stress ranges. They suggested that it could be generally applicable to predict the failure location and the fatigue life at welds of interest. The application of the master S-N curve approach for fatigue analysis of breathing webs through FE simulation of multiple plate girders is illustrated and the effect of initial out-of-plane displacement as an important geometrical parameter in the girders' fatigue behavior is investigated by Mojgan [6]. A simplified version of master S-N curve method, which needs even less experimental input, using an assumption of constant S-N curve slope is presented by Atul [7]. Dong etc. have carried on the reprocessing of thousands of fatigue test results data of steel structure welded joint in the last 50 years. The master S-N curve for fatigue design based on equivalent structural stress range is determined by linear regression analysis. Statistical results show that the scatter level of all S-N samples represented by standard deviations is about 0.25 [8]. In order to further reduce the scatter degree of S-N curves and to improve the fatigue life prediction accuracy, rough set theory is used for analysis of the factors which influence the fatigue life of the aluminum alloy welded joints.

Rough set theory (RST) [9], proposed by Pawlak, has been successfully used as a new feature reduction tool to discover data dependencies and reduce the number of features contained in a dataset. The traditional RST-based feature reduction algorithms are established on the equivalence relation and only compatible for categorical datasets. Discretization should be conduct when processing continuous numerical data, which would lead to losing of information [10,11]. To overcome this drawback, many extensions of RST have been proposed, such as fuzzy rough sets [12, 13], tolerance approximate models [14, 15], covering approximate model [16, 17] and neighborhood granular model [18, 19]. Among all the extensions, neighborhood rough set model can process both numerical and categorical data set via the $\delta$-neighborhood set, which will not break the neighborhood and order structure of dataset in real spaces [20]. To reduce information loss, neighborhood rough set theory is used here to determine the fatigue characteristics domain.

Three-point bending fatigue test of 5083 and 5A06 aluminum alloy T-welded joints is carried out in this work to further demonstrate the applicability and validity of the S-N curve modeling method based on the fatigue characteristics domain. Fatigue characteristic domains are determined and a set of S-N curves correspond to the different fatigue characteristic domain are obtained. Statistical analysis is carried out and a case study of fatigue life prediction of 5083 aluminum alloy Twelded joint is conducted. The results of case study show that the predicted result is in good agreement with the test result.

\section{METHODOLOGY}

\section{Basic Principle of the master $S-N$ curve approach}

he nodal force based structural stress method is based on equilibrium-equivalent decomposition of an arbitrary stress state at a location of interest such as at weld toe (Fig. 1) into an equilibrium-equivalent structural stress part and a self-equilibrating notch-stress part [3]. The equivalent structural stress is described as

$$
\sigma_{s}=\sigma_{m}+\sigma_{b}
$$

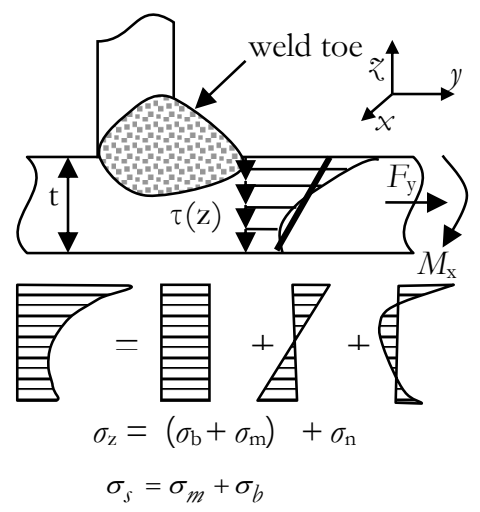

Figure 1: Stress distribution at the weld toe. 
Suppose $l$ represents the length of the weld toe line, the plate thickness is $t$, the force vertical to the welding toe is $F_{y}$, the bending moment around the welding toe is $M_{x}, f_{y}$ is line force and $m_{x}$ is line moment, according to the mechanical formula of the material as shown in Eqn. (2), the structural stress can be calculated as Eqn. (3) and (4).

$$
\begin{aligned}
& \sigma_{m}=\frac{F y}{A}=\frac{F y}{l \cdot t} \quad, \sigma_{b}=\frac{M_{x}}{W}=\frac{M_{x}}{\frac{1}{6} \cdot l \cdot t^{2}} \\
& f_{y}=F y / l, m_{x}=M_{x} / l \\
& \sigma_{s}=\sigma_{m}+\sigma_{b}=\frac{f_{y}}{t}+\frac{6 m_{x}}{t^{2}}
\end{aligned}
$$

An equivalent structural stress range parameter can be defined as:

$$
\Delta S_{s}=\frac{\Delta \sigma_{s}}{t \frac{2-m}{2 m} \cdot I(r) \frac{1}{m}}
$$

where $\Delta \sigma_{S}$ represents the structural stress range calculated, $I(r)$ is a dimensionless parameter derived by fracture mechanics considerations, and $m$ is the crack propagation exponent in the conventional Paris law, taking on a value of about 3.6 [21]. It could be seen that the equivalent structural stress parameter described in Eqn. (5) can capture the effects of stress concentration, plate thickness and loading mode effects on fatigue behavior of welded components.

The formula for fatigue life calculation of welded joints using the equivalent structural stress $\Delta S_{s}$ can be expressed as

$$
\Delta S_{s}=C N^{b}
$$

where $N$ is the number of cycles which indicate the fatigue life of the structure, $C$ is material constant and $h$ represents the negative slope of the master S-N curve. By performing regression analysis with respect to the cycles to failure, Tab. 1. summarizes the statistical parameters of the master S-N curve in terms of the mean, $\pm 1 \sigma, \pm 2 \sigma, \pm 3 \sigma$ [21].

\begin{tabular}{ccccc}
\hline Statistical Basis & Ferritic and stainless Steels & Aluminum & \\
& $\mathrm{C}$ & $\mathrm{h}$ & $\mathrm{C}$ & $\mathrm{h}$ \\
Mean & 19930.2 & & 3495.13 & \\
$+1 \sigma$ (upper 68\%) & 23885.8 & & 4293.19 & \\
$-1 \sigma($ lower 68\%) & 16629.7 & -0.32 & 2845.42 & \\
$+2 \sigma($ upper 95\%) & 28626.5 & & 5273.48 & -0.28 \\
$-2 \sigma($ lower 95\%) & 13875.7 & & 2316.48 & \\
$+3 \sigma$ (upper 99\%) & 34308.1 & & 6477.60 & \\
$-3 \sigma($ lower 99\%) & 11577.9 & & 1885.87 \\
\hline
\end{tabular}

Table1: Coefficients of master S-N curve.

\section{Fatigue characteristics domain}

Rough set theory can objectively obtain the key fatigue life influencing factors set of welded joints from the data of fatigue test specimens of welded joints. The fatigue samples with the same value of the key fatigue life influencing factors of the welded joints are distributed in a relatively independent area, which is called fatigue characteristics domain. The calculation 
of weights is a quantitative description of the extent to which various key influencing factors affect fatigue life. If there are too many key fatigue life influencing factors in the neighborhood rough set attributes reduction results, the number of the key factors could be appropriately reduced by increasing the criticality threshold of the influencing factors so as to reduce the number of the fatigue characteristics domains. The basic process for determine of the fatigue characteristics domains is shown in Fig. 2.

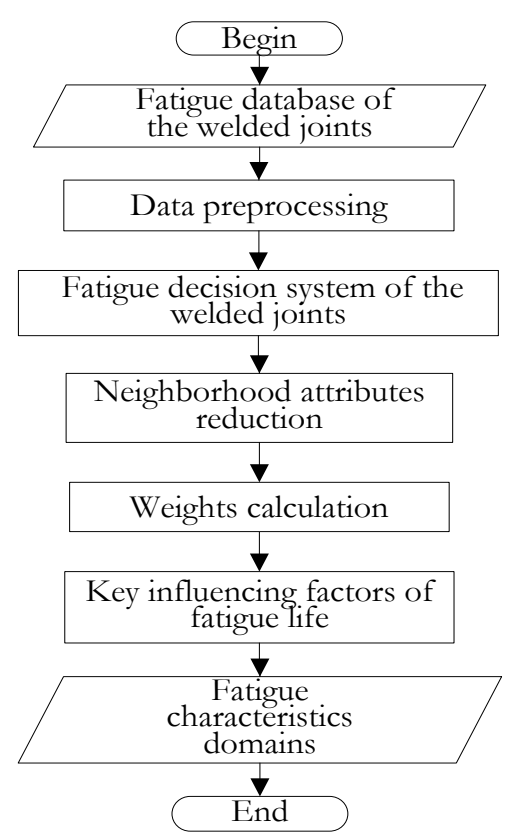

Figure 2: Process of determining of the fatigue characteristics domain.

Among all the steps in the process of determining the fatigue characteristics domain, the neighborhood attributes reduction step is the most important. A forward greedy algorithm is used for attributes reduction as described in [21]. The forward greedy algorithm includes the following 7 steps.

Step 1: Input the fatigue decision system $<U, C, D, \delta>$ and the attribute importance threshold $\varepsilon$. Where $U=\left\{x_{1}, x_{2}, \ldots x_{n}\right\}$ is a nonempty finite set of objects called the universe, $C$ is the condition features set, $C=\left\{a_{1}, a_{2}, \ldots, a_{n}\right\}, D$ is the set of decision features, and $\delta$ is the neighborhood parameter $(0 \leq \delta \leq 1)$. For the fatigue decision system here, $U$ is the set of all the fatigue specimens, $C$ is the set of the fatigue life influencing factors of the welded joints, $D$ is the fatigue life of the welded joints.

Step 2: For each condition attribute $a_{i} \in C$, compute the neighborhood radius $\delta\left(a_{i}\right)=S T D\left(a_{i}\right) / \lambda$, where $\operatorname{STD}\left(a_{i}\right)$ represents the average value of the attribute $a_{i}$, and $\lambda$ is a neighborhood radius calculation parameter, its value is usually between $2 \sim 4$.

Step 3: Let $\phi \rightarrow R E D$.

Step 4: For each $a_{i} \in C-\operatorname{Re} d$ compute the significance of $a_{i}, \quad \operatorname{SIG}(a i, \operatorname{Re} d, D)=\gamma_{\operatorname{Re} d \cup a i}(D)-\gamma_{\operatorname{Re} d}(D)$ where $\gamma_{\operatorname{Re} d}(D)=\frac{|\underline{N R} d D|}{|U|}$ is attribute dependence, $\quad \underline{N}_{\operatorname{Re} d} D=\left\{x_{i} \mid \delta_{\operatorname{Re} d}\left(x_{i}\right) \subseteq D, x_{i} \in U\right\}$ is the lower approximate set, $\delta\left(x_{i}\right)=\left\{x \in U, \Delta\left(x, x_{i}\right) \leq \delta\right\}, \Delta(x, y)$ is a distance function, which satisfies

(1) $\Delta(x, y) \geq 0$;

(2) $\Delta(x, y)=0$, if and only if $\mathrm{x}=\mathrm{y}$;

(3) $\Delta(x, y)=\Delta(y, x)$;

(4) $\Delta(x, y)+\Delta(y, z) \geq \Delta(x, z)$.

Step 5: Select the attribute $a_{k}$ with the maximum significance value in the conditional attribute sets.

Step 6: Determine whether the significance value of the attribute $a_{k}$ is greater than the given threshold value, if it is true then go to step 4, otherwise go to step 7.

Step 7: Return the reduction results RED, exit. 


\section{EXPERIMENT}

hree-point bending fatigue experiment is carried out to test the fatigue life of specimens. First of all, material of the specimens and welding technology are introduced, then the three-point bending fatigue test of aluminum alloy

T-welded joints is described, after that finite element model of T-joint is established, hot spot stress is calculated and equivalent structural stress transformation is accomplished. Master S-N curve for design together with the S-N curves cluster according to the fatigue characteristic domain are fitted. Finally, the S-N curve cluster and the master S-N curve are compared and a case study is analyzed.

\section{Material of the specimens}

Materials of the specimens used in the experiment are 5083 and 5A06 aluminum alloy. These two kinds of aluminum alloy belong to non-heat treatment aluminum alloy material in Al-Mg alloy. The chemical composition and mechanical properties of the materials are shown in Tab. 2 and Tab. 3 respectively.

The welding material is 5183 aluminum alloy welding wire and the diameter of the welding wire is $1.2 \mathrm{~mm}$. The chemical composition of deposited metal is shown in Tab. 4, and the protective gas used is Ar.

\begin{tabular}{|c|c|c|c|c|c|c|c|c|c|c|}
\hline \multicolumn{2}{|c|}{ Material Brand } & $\mathrm{Si}$ & $\mathrm{Fe}$ & $\mathrm{Cu}$ & $\mathrm{Mn}$ & $\mathrm{Mg}$ & $\mathrm{Cr}$ & $\mathrm{Zn}$ & $\mathrm{Ti}$ & $\mathrm{Al}$ \\
\hline \multirow{2}{*}{5083} & measured & 0.1 & 0.25 & 0.04 & 0.62 & 4.68 & 0.11 & 0.02 & 0.10 & other \\
\hline & standard & $\leq 0.40$ & $\leq 0.40$ & $\leq 0.10$ & $0.40 \sim 1.0$ & $4.0 \sim 4.9$ & $0.05 \sim 0.25$ & $\leq 0.25$ & $\leq 0.15$ & other \\
\hline \multirow{2}{*}{$5 \mathrm{~A} 06$} & measured & 0.15 & 0.25 & 0.05 & 0.62 & 6.54 & / & 0.02 & 0.04 & other \\
\hline & standard & $\leq 0.40$ & $\leq 0.40$ & $\leq 0.10$ & $0.50 \sim 0.80$ & $5.8 \sim 6.8$ & / & $\leq 0.20$ & $0.02 \sim 0.10$ & other \\
\hline
\end{tabular}

Table 2: Chemical composition of test materials (\%).

\begin{tabular}{|c|c|c|c|c|c|c|c|c|}
\hline \multirow[b]{2}{*}{ Material Brand } & \multicolumn{5}{|c|}{ Tensile test } & \multicolumn{3}{|l|}{ Bend test } \\
\hline & $\begin{array}{l}\text { Thickness } \\
\text { / mm }\end{array}$ & $\begin{array}{c}\mathrm{R}_{\mathrm{m}} \\
/ M P a\end{array}$ & $\begin{array}{l}\mathrm{R}_{\mathrm{p} 0.2} \\
/ \mathrm{MPa}\end{array}$ & $\begin{array}{c}\mathrm{A} \\
/ \%\end{array}$ & $\begin{array}{l}\text { Bend diameter } \\
\qquad / \mathrm{mm}\end{array}$ & $\begin{array}{c}\text { Bend angle } \\
1{ }^{\circ}\end{array}$ & result & $\begin{array}{c}\text { Hardness } \\
\text { HB }\end{array}$ \\
\hline \multirow{4}{*}{5083} & \multirow{2}{*}{6} & 350 & 220 & 17.5 & \multirow{2}{*}{36} & \multirow{2}{*}{180} & No cracks & \multirow{2}{*}{84.4} \\
\hline & & 345 & 220 & 15.5 & & & No cracks & \\
\hline & \multirow{2}{*}{10} & 320 & 192 & 19.5 & \multirow{2}{*}{60} & \multirow{2}{*}{180} & No cracks & \multirow{2}{*}{79.1} \\
\hline & & 320 & 195 & 19.0 & & & No cracks & \\
\hline \multirow{6}{*}{$5 \mathrm{~A} 06$} & \multirow{2}{*}{6} & 345 & 177 & 24.5 & \multirow{2}{*}{36} & \multirow{2}{*}{180} & No cracks & \multirow{2}{*}{84.9} \\
\hline & & 345 & 184 & 18.5 & & & No cracks & \\
\hline & \multirow{2}{*}{12} & 350 & 166 & 26.0 & \multirow{2}{*}{72} & \multirow{2}{*}{180} & No cracks & \multirow{2}{*}{83.9} \\
\hline & & 350 & 168 & 27.0 & & & No cracks & \\
\hline & \multirow{2}{*}{16} & 345 & 154 & 28.0 & \multirow{2}{*}{96} & \multirow{2}{*}{180} & No cracks & \multirow{2}{*}{83.9} \\
\hline & & 345 & 154 & 29.5 & & & No cracks & \\
\hline
\end{tabular}

Table 3: Mechanical properties of test materials.

\begin{tabular}{cccccccc}
\hline Material name & $\mathrm{Si}$ & $\mathrm{Cu}$ & $\mathrm{Mn}$ & $\mathrm{Mg}$ & $\mathrm{Cr}$ & $\mathrm{Zn}$ & $\mathrm{Al}$ \\
5183 & 0.4 & 0.10 & $0.5 \sim 1.0$ & $4.3 \sim 5.2$ & $0.05 \sim 0.25$ & 0.25 & other \\
\hline
\end{tabular}

Table 4: Chemical composition of 5183 aluminum alloy welding wire. 


\section{Welding process}

MIG welding method with the Austria Fronius welding machine is used in the experiment here. The T-welded joints specimen has $\mathrm{K}$ type groove, the groove angle is $55^{\circ}$, without leaving blunt edge, the interval is $1-2 \mathrm{~mm}$, tests of the $\mathrm{T}$ joints made of 5083 and 5A06 aluminum alloy with different thickness are carried out respectively. X - ray flaw detection is carried out after welding, and three-point bending fatigue experiment of 5A06+5083 T-joint and 5A06+5A06 T-joint are made. The relevant welding parameters of the T-joints are shown in Tab.5.

\begin{tabular}{|c|c|c|c|c|c|c|c|c|}
\hline Material & $\begin{array}{l}\text { Thickness } \\
\text { /mm }\end{array}$ & $\begin{array}{l}\text { Groove } \\
\text { form }\end{array}$ & Layers & $\begin{array}{c}\text { Welding } \\
\text { current } \\
\text { /A }\end{array}$ & $\begin{array}{c}\text { Welding } \\
\text { voltage } \\
\text { /V }\end{array}$ & $\begin{array}{c}\text { Welding } \\
\text { speed } \\
/ \mathrm{mm} / \mathrm{s}\end{array}$ & $\begin{array}{c}\text { Gas } \\
\text { flow } \\
\text { /L/min }\end{array}$ & $\begin{array}{c}\mathrm{X} \text { ray flaw } \\
\text { detection } \\
\text { rating }\end{array}$ \\
\hline \multirow{4}{*}{$\begin{array}{c}5 \mathrm{~A} 06+ \\
5083\end{array}$} & \multirow{4}{*}{$16+10$} & \multirow{4}{*}{$\mathrm{K}$} & 1 & 210 & 24.2 & 7.0 & 20 & \multirow{4}{*}{ II } \\
\hline & & & 2 & 240 & 24.8 & 7.45 & 20 & \\
\hline & & & 3 & 220 & 26.6 & 4.61 & 20 & \\
\hline & & & 4 & 220 & 26.6 & 4.56 & 20 & \\
\hline \multirow{6}{*}{$\begin{array}{c}5 \mathrm{~A} 06+ \\
5 \mathrm{~A} 06\end{array}$} & \multirow{6}{*}{$35+16$} & \multirow{6}{*}{$\mathrm{K}$} & 1 & 220 & 26.6 & 7.29 & 20 & \multirow{6}{*}{ I } \\
\hline & & & 2 & 236 & 24.8 & 7.78 & 20 & \\
\hline & & & 3 & 220 & 26.6 & 5.93 & 20 & \\
\hline & & & 4 & 220 & 26.6 & 5.30 & 20 & \\
\hline & & & 5 & 220 & 27.4 & 5.30 & 20 & \\
\hline & & & 6 & 220 & 27.4 & 4.86 & 20 & \\
\hline
\end{tabular}

Table 5: Welding parameters of T-welded joints.

Three-point bending fatigue test of $T$-joint

The experiment is carried out in accordance with JB/T7716-95. Size and shape of the specimen in the three-point bending fatigue test are shown in Fig. 3. The thickness of the T-welded joint expressed as $a$ in Fig. 3. In this work, the nominal value of $a$ is $8.6 \mathrm{~mm}$ for the $5 \mathrm{~A} 06+5083 \mathrm{~T}$-joint and it is $14.9 \mathrm{~mm}$ for the $5 \mathrm{~A} 06+5 \mathrm{~A} 06 \mathrm{~T}$-joint. PLG-100 microcomputer controlled high frequency fatigue testing machine is used for the three-point bending fatigue test of $\mathrm{T}$-joint. Other technical specifications in the test are: the precision of the static load is $\pm 1 \%$, the average fluctuation of dynamic load is $\pm 1 \%$, the amplitude fluctuation of dynamic load is $\pm 2 \%$. The loading mode of the three-point bending fatigue test is shown in Fig. 4. Span of fulcrum of the 5A06+5A06 T-joint is $100 \mathrm{~mm}$, and that of the $5 \mathrm{~A} 06+5083 \mathrm{~T}$-joint is $60 \mathrm{~mm}$. Vibration frequency for $5 \mathrm{~A} 06+5 \mathrm{~A} 06 \mathrm{~T}$-joint is $170 \mathrm{HZ}$, and for $5 \mathrm{~A} 06+5083 \mathrm{~T}$-joint, it is $160 \mathrm{HZ}$. During the test, when the crack size at the weld toe is large enough causing the load not to go up, automatically unload and stop vibration, then record the cycle times. The cyclic stress ratio used in the test is $\mathrm{R}=0.1$, and the designated cycle life is $1 \times 10^{7}$.

Ten 5A06+5A06 and ten 5A06+5083 T-joints specimens are used in the three-point bending fatigue test. Fatigue life data of the specimens obtained in the test are shown in Tab. 6.

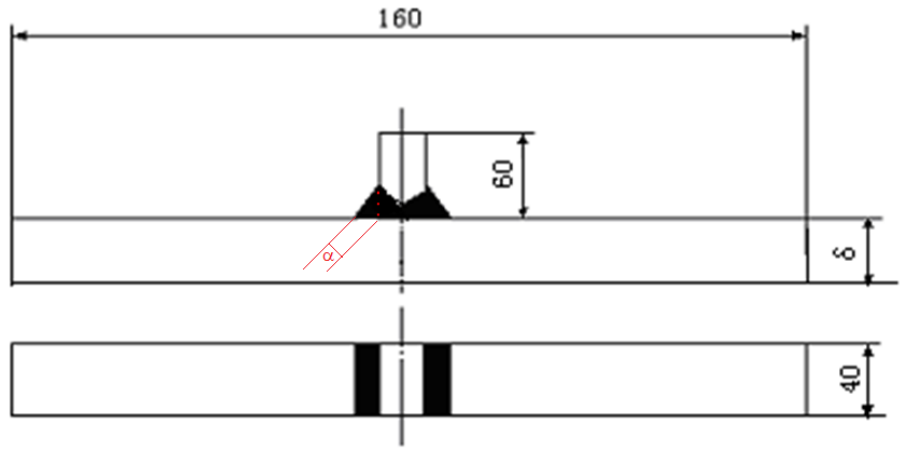

Figure 3: Size and shape of the three-point bending fatigue specimen. 


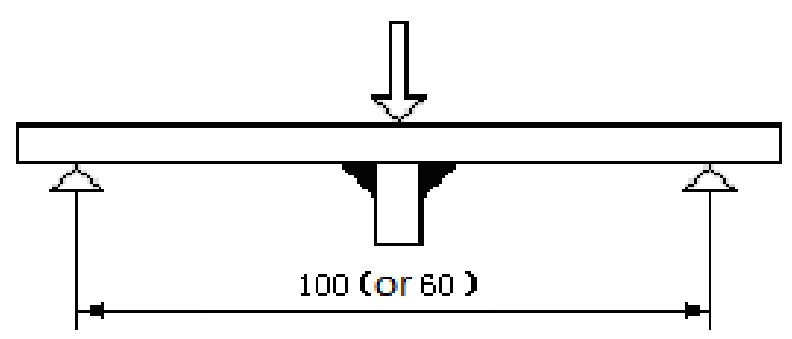

Figure 4: Loading mode of T-joint specimen.

\begin{tabular}{|c|c|c|c|c|c|c|}
\hline Material & $\begin{array}{l}\text { Specimen } \\
\text { number }\end{array}$ & $\begin{array}{l}\text { Load } \\
\text { frequency } \\
\quad(H Z)\end{array}$ & $\begin{array}{l}\sigma_{\max } \\
M P a\end{array}$ & $\begin{array}{l}\text { Cycle numbers } \\
\text { when crack } \\
\qquad\left(\times 10^{6}\right)\end{array}$ & $\begin{array}{l}\text { Fracture } \\
\text { location }\end{array}$ & note \\
\hline \multirow{10}{*}{$5 A 06+5083$} & $1-1$ & 163 & 75.0 & 0.4521 & weld toe & \multirow{10}{*}{ Clip holding problem } \\
\hline & $1-2$ & 174 & 70.0 & 0.9885 & weld toe & \\
\hline & $1-3$ & 171 & 80.0 & 0.2257 & weld toe & \\
\hline & $1-4$ & 151 & 60.0 & $>10$ & $\begin{array}{l}\text { without } \\
\text { fracture }\end{array}$ & \\
\hline & $1-5$ & 150 & 70.0 & 2.08 & weld toe & \\
\hline & $1-6$ & 159 & 60.0 & 3.3749 & weld toe & \\
\hline & $1-7$ & 163 & 55.0 & $>10$ & $\begin{array}{l}\text { without } \\
\text { fracture }\end{array}$ & \\
\hline & $1-8$ & 162 & 60.0 & 4.3542 & weld toe & \\
\hline & $1-9$ & 159 & 55.0 & $>10$ & $\begin{array}{l}\text { without } \\
\text { fracture }\end{array}$ & \\
\hline & $1-10$ & 171 & 60.1 & 5.7485 & weld toe & \\
\hline \multirow{10}{*}{$5 \mathrm{~A} 06+5 \mathrm{~A} 06$} & $2-1$ & 158 & 80.0 & 0.2729 & weld toe & \multirow{10}{*}{$\begin{array}{l}\text { Weld toe is not fused } \\
\text { There is a scratch } 2 \mathrm{~mm} \\
\text { around the weld toe }\end{array}$} \\
\hline & $2-2$ & 158 & 70.0 & 0.7759 & weld toe & \\
\hline & $2-3$ & 159 & 40.0 & 8.7281 & weld toe & \\
\hline & $2-4$ & 164 & 35 & $>10$ & $\begin{array}{l}\text { without } \\
\text { fracture }\end{array}$ & \\
\hline & $2-5$ & 170 & 37.5 & $>10$ & $\begin{array}{l}\text { without } \\
\text { fracture }\end{array}$ & \\
\hline & $2-6$ & 172 & 40.0 & 4.3287 & weld toe & \\
\hline & $2-7$ & 172 & 37.5 & 9.3184 & weld toe & \\
\hline & $2-8$ & 170 & 35 & $>10$ & \multirow{3}{*}{$\begin{array}{l}\text { without } \\
\text { fracture } \\
\text { without } \\
\text { fracture } \\
\text { weld toe }\end{array}$} & \\
\hline & $2-9$ & 170 & 37.5 & $>10$ & & \\
\hline & $2-10$ & 170 & 40.0 & 6.3685 & & \\
\hline
\end{tabular}

Table 6: Three-point bending fatigue test data of 'T-joints.

where $\sigma_{\max }$ is computed through Eqn. (7) (9), which is the maximum bending fatigue stress, $M$ is the maximum bending moment, $\omega$ is the anti-bending section coefficient, $F$ is the load applied, $L_{S}$ is the distance between pivots, $b$ is the width of the specimen, $b$ is the thickness of the specimen.

$$
\begin{gathered}
\sigma_{\max }=\frac{M}{\omega} \\
M=\frac{F L_{S}}{4}
\end{gathered}
$$




$$
\omega=\frac{b b^{2}}{6}
$$

\section{Finite element model of T-joints}

Material properties used in the FE analysis are shown in Tab.7 and the finite element type is C3D8R. The size of the mesh refinement will not influence the calculation result of the nodal force based structural stress and the element size is not unified here. According to the size of the specimens of 5A06+5083 T-joint and 5A06+5A06 T-joint, the corresponding finite element model is established as shown in Fig. 5 and Fig. 6. Position of the fulcrum in the test is determined according to JBT 7716-1995. For the 5A06+5083 T-joints, the span of fulcrum is $60 \mathrm{~mm}$, and for the 5A06+5A06 Tjoints, the span of fulcrum is $100 \mathrm{~mm}$. The loading mode of the 5A06+5083 T-joint is shown in Fig. 7.

\begin{tabular}{cccc}
\hline Material & $\begin{array}{c}\text { Density } \\
\left(\mathrm{Kg} / \mathrm{mm}^{3}\right)\end{array}$ & $\begin{array}{c}\text { Young modulus } \\
(\mathrm{MPa})\end{array}$ & Poisson ratio \\
$5 \mathrm{~A} 06$ & $2.7 \mathrm{e}-9$ & 71000 & 0.33 \\
5083 & $2.72 \mathrm{e}-9$ & 71016 & 0.33 \\
5183 & $2.66 \mathrm{e}-9$ & 70327 & 0.33 \\
\hline
\end{tabular}

Table 7: Material properties.

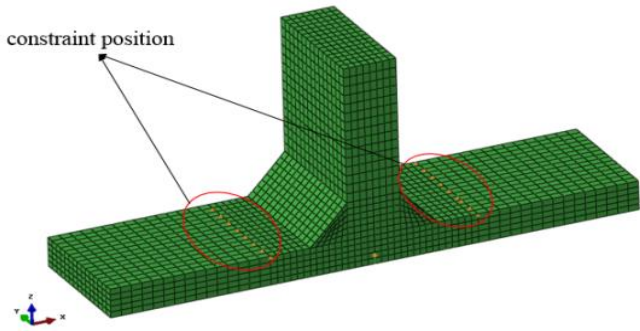

Figure 5: Finite element model of 5A06+5083 T-joint.

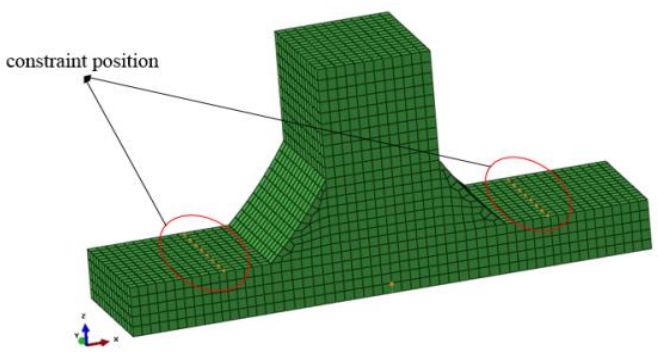

Figure 6: Finite element model of 5A06+5A06 T-joint.

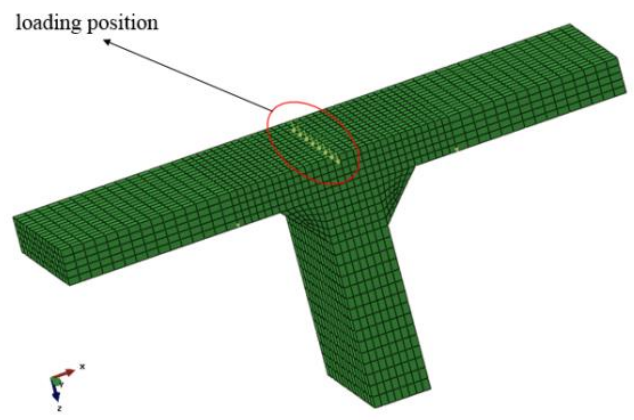

Figure 7: Loading position of 5A06+5083 T-joint.

\section{Structural stress computation}

ABAQUS software is used to simulate the $5 \mathrm{~A} 06+5083 \mathrm{~T}$-joint and the $5 \mathrm{~A} 06+5 \mathrm{~A} 06 \mathrm{~T}$-joint so that the nodal force at weld toe is computed. The detailed calculation process of structural stress and equivalent structural stress could be found in reference [1,2]. For example, the nodal force computation result of $5 \mathrm{~A} 06+5083$ T-joint when $\sigma_{\max }=70 \mathrm{MPa}$ and the nodal force computation result of $5 \mathrm{~A} 06+5083 \mathrm{~T}$-joint when $\sigma_{\max }=80 \mathrm{MPa}$ are shown as in Fig. 8 and Fig. 9. The thickness of the 5A06+5083 T-joint shown as $a$ in Fig. 3 is $8.6 \mathrm{~mm}$ and it is $14.9 \mathrm{~mm}$ for the 5A06+5A06 T- joint. 


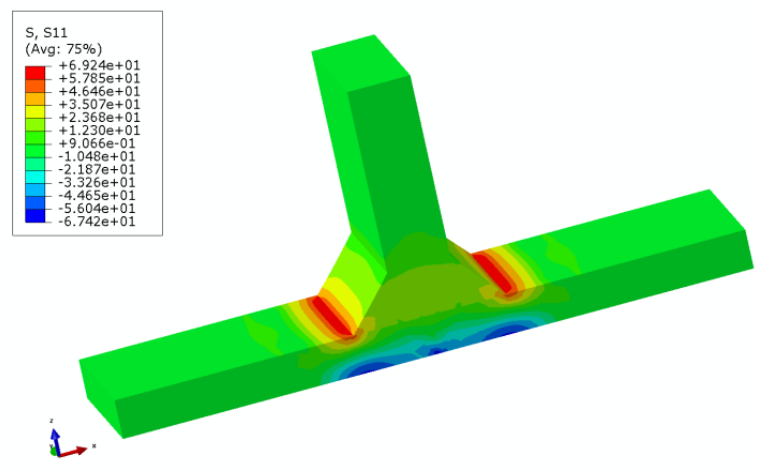

Figure 8: Stress results of 5A06+5083 T-joint.

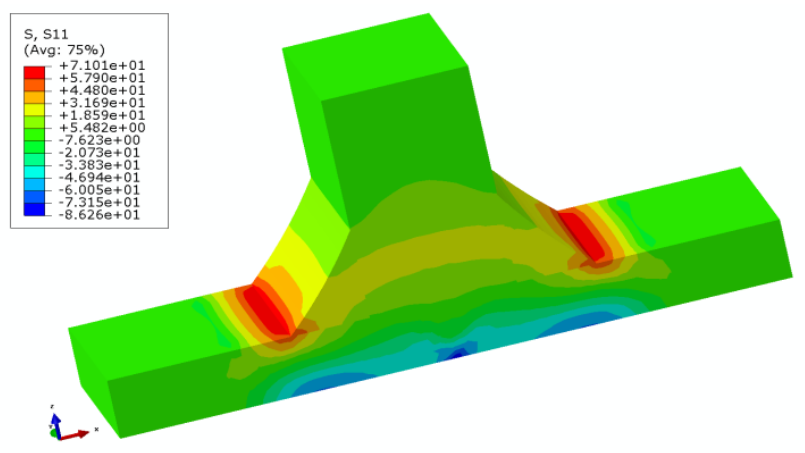

Figure 9: Stress results of 5A06+5A06 T-joint.

According to the results of nodal force, Verity module in the FE-SAFE software is used for structural stress computation and equivalent structural stress transformation at weld toe. Computation results of the 5A06+5083 $\mathrm{T}$-joint and 5A06+5A06 T-joint are obtained as shown in Tab.8.

\begin{tabular}{cccccc}
\hline Material & $\begin{array}{c}\text { Specimen } \\
\text { number }\end{array}$ & $\begin{array}{c}\sigma_{\max } \\
M P a\end{array}$ & $\begin{array}{c}\text { Structural } \\
\text { stress } \\
(M P a)\end{array}$ & $\begin{array}{c}\text { Equivalent structural stress } \\
\text { range } \\
(M P a)\end{array}$ & $\begin{array}{c}\text { Cycle numbers when } \\
\text { crack } \\
\left(\times 10^{6}\right)\end{array}$ \\
5 5A06+5083 & $1-1$ & 75 & 51.99 & 81.19 & 0.4521 \\
& $1-3$ & 80 & 55.45 & 86.61 & 0.2257 \\
& $1-5$ & 70 & 48.52 & 75.78 & 2.08 \\
& $1-7$ & 60 & 41.59 & 64.95 & 3.3542 \\
& $1-9$ & 60 & 41.59 & 64.95 & 5.7485 \\
& $1-11$ & 60.1 & 42.28 & 66.04 & 0.2729 \\
& $2-1$ & 80 & 74.75 & 129.69 & 1.3366 \\
& $2-2$ & 60 & 56.06 & 97.27 & 2.3358 \\
& $2-3$ & 50 & 46.72 & 81.06 & 8.7281 \\
& $2-4$ & 40 & 37.38 & 64.85 & 4.3287 \\
\hline
\end{tabular}

Table 8: Computation results of structural stress and equivalent structural stress range.

\section{RESULTS}

\section{Master S-N curve for fatigue design}

A ccording to the results of three-point bending fatigue test and the data collected from related literatures [22-25], fatigue database of aluminum alloy welded joints is established. Some of the data in the database are shown in the

following Tab.9. There are 76 samples in the database including 7 types of materials, 4 kinds of welding methods, 6 types of plate thickness whose range is from $2.5 \mathrm{~mm}$ to $16 \mathrm{~mm}$, three cases of stress ratio including $0,0.1$ and $0.5,3$ kinds of loading type including tensile( $\mathrm{T}$ ), four point bending (4B) and three-point bending(3B), 3 kinds of joint type including T-joints, lap joints and butt joints.

The fatigue test data of aluminum alloy welded joints is analyzed by using MATLAB software, and S-N curve is expressed in the form of $\lg S=A+B \lg N$. On bi-logarithmic coordinate, mean $\mathrm{S}-\mathrm{N}$ curve of the test samples based on 
equivalent structural stress range is fitted by using least square method as Mean1 in Fig. 10. Mean of the master S-N curve defined in Tab. 1 is shown as Mean2 in Fig. 10. Goodness-of-fit statistics of Master S-N curve by using Eq.SS Range is shown in Tab.10. For more detailed about the definition of SSE, R-square, Adjusted R-square and RMSE, please see reference [26].

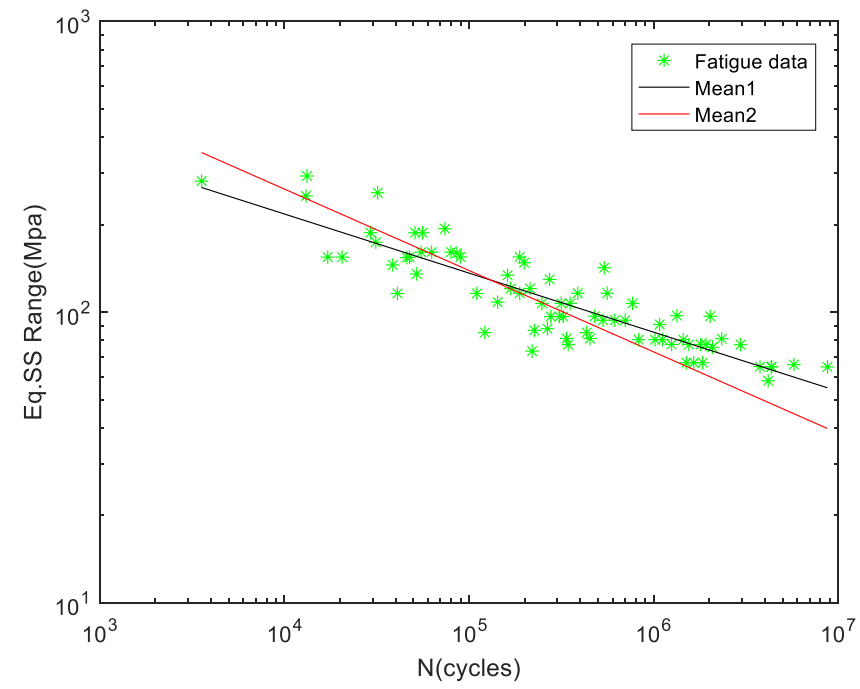

Figure 10: Master S-N curve based on Eq. SS Range.

\begin{tabular}{|c|c|c|c|c|c|c|c|}
\hline $\begin{array}{l}\text { Material } \\
\text { type }\end{array}$ & $\begin{array}{l}\text { Welding } \\
\text { method }\end{array}$ & $\begin{array}{c}\text { Thickness } \\
(\mathrm{mm})\end{array}$ & Ratio & $\begin{array}{l}\text { Loading } \\
\text { type }\end{array}$ & $\begin{array}{l}\text { Joint } \\
\text { type }\end{array}$ & $\begin{array}{c}\text { Equivalent structural stress } \\
\text { range }(M P a)\end{array}$ & $\begin{array}{l}\text { Life } \\
\text { cycles }\end{array}$ \\
\hline 5083 H11 & MIG & 10 & 0.1 & $4 \mathrm{~B}$ & TJ:p & 187.6994 & 29250 \\
\hline 5083 H11 & MIG & 10 & 0.1 & $4 \mathrm{~B}$ & TJ:p & 160.8852 & 55000 \\
\hline $\mathrm{AlMg} 4 \mathrm{MnCr}$ & GMAW & 2.5 & 0.1 & $\mathrm{~T}$ & LJ_SS:p & 154.7135 & 20540 \\
\hline $\mathrm{AlMg} 4 \mathrm{MnCr}$ & GMAW & 2.5 & 0.1 & $\mathrm{~T}$ & LJ_SS:p & 85.0924 & 121730 \\
\hline $\begin{array}{l}\mathrm{AlMgSi1} \\
(6082)\end{array}$ & TIG & 3 & 0 & $\mathrm{~T}$ & LJ_DS:p & 294.1392 & 13250 \\
\hline $\begin{array}{l}\text { AlMgSi1 } \\
(6082)\end{array}$ & TIG & 3 & 0 & $\mathrm{~T}$ & LJ_DS:p & 159.7613 & 85920 \\
\hline NP5/6 & Manual Arc & 4.76 & 0 & $\mathrm{~T}$ & SJ_DS:p & 154.9481 & 90000 \\
\hline HР30 & Manual Arc & 4.76 & 0 & $\mathrm{~T}$ & SJ_DS:p & 116.2111 & 188000 \\
\hline $5 \mathrm{~A} 06+5083$ & MIG & 10 & 0.1 & $3 \mathrm{~B}$ & $\mathrm{~T}$ & 81.19 & 452100 \\
\hline $5 \mathrm{~A} 06+5 \mathrm{~A} 06$ & MIG & 16 & 0.1 & $3 \mathrm{~B}$ & $\mathrm{~T}$ & 129.69 & 272900 \\
\hline
\end{tabular}

Table 9: Fatigue data of aluminum alloy welded joints.

\begin{tabular}{cc}
\hline SSE & Mean value \\
R-square & 0.4389 \\
Adjusted R-square & 0.7929 \\
RMSE & 0.7901 \\
\hline
\end{tabular}

Table 10: Goodness-of-fit statistics of master S-N curve by using Eq.SS range.

Expression of the mean S-N curve of aluminum alloy welded joint based on the Eq.SS range obtained in the experiment is shown as the following Eqn.(10). 


$$
\lg \Delta S=3.144-0.2018 \lg N
$$

\section{S-N curves cluster based on fatigue characteristic domain}

Neighborhood fatigue decision system is constructed according to the established fatigue database of aluminum alloy welded joints. Feature reduction of this neighborhood fatigue decision system is accomplished by using the forward greedy algorithm. The reduction result we get in the experiment is Material type, Ratio, Equivalent structural stress range $\}$. Accordingly, fatigue characteristic domain is divided based on the reduction result and we get the 8 fatigue characteristic domains from $S_{1}$ to $S_{8}$. In domain $S_{1}$, material type is $5083 \mathrm{H} 11$ and ratio is 0.1 . In domain $S_{2}$, material type is $5083 \mathrm{H} 11$ and ratio is 0.5 . In domain $S_{3}$, material type is $A l M g 4 \mathrm{MnCr}$ and ratio is 0.1 . In domain $S_{4}$, material type is AlMgSi1(6082) and ratio is 0 . In domain $S_{5}$, material type is NP5/6 and ratio is 0 . In domain $S_{6}$, material type is HP30 and ratio is 0 . In domain $S_{7}$, material type is $5 \mathrm{~A} 06+5083$ and ratio is 0.1 . In domain $S_{8}$, material type is $5 \mathrm{~A} 06$ and ratio is 0.1 . S$\mathrm{N}$ curves are fitted in each fatigue characteristic domain, and the $\mathrm{S}-\mathrm{N}$ curves cluster we get in the experiment are shown in Fig. 11. Where Mean 7 and Mean 8 corresponds to the 5A06+5083 and the 5A06+5A06 T-joints respectively. Goodness-offit statistics of Mean 7 and Mean 8 are shown in Tab. 11.

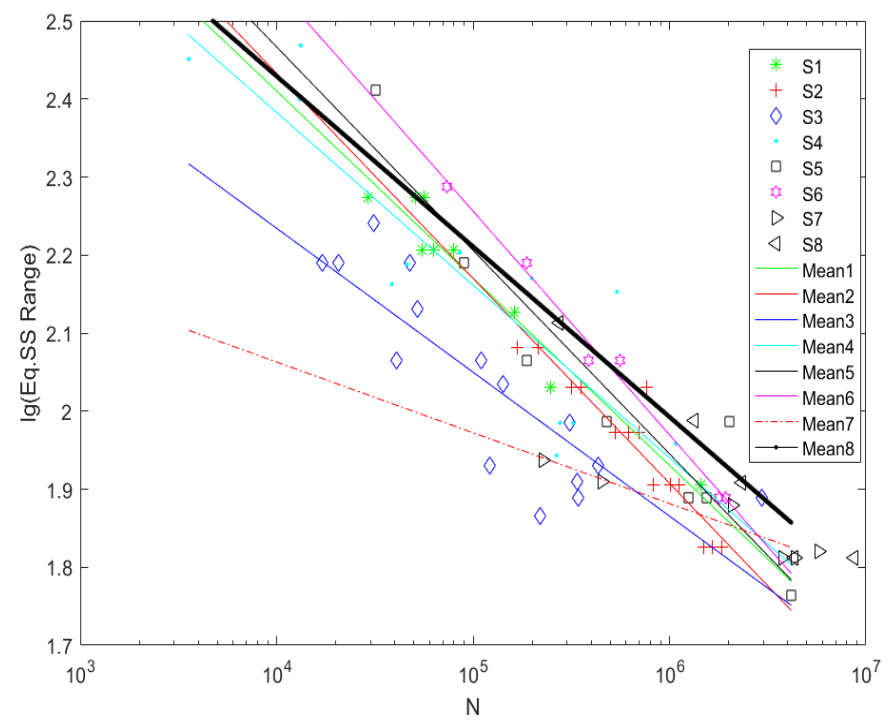

Figure 11: S-N curve cluster based on the fatigue characteristic domain.

\begin{tabular}{ccc}
\hline & Mean $_{7}$ & Mean $_{8}$ \\
SSE & 0.0012 & 0.0029 \\
R-square & 0.9202 & 0.9555 \\
Adjusted R-square & 0.9002 & 0.9406 \\
RMSE & 0.0173 & 0.0311 \\
\hline
\end{tabular}

Table 11: Goodness-of-fit statistics of Mean7-Mean8.

The S-N curve equation of Mean7 and Mean 8 are shown as the following (11) and (12).

$$
\begin{aligned}
& \lg \Delta S=2.426-0.0907 \lg N \\
& \lg \Delta S=3.302-0.2183 \lg N
\end{aligned}
$$

From the process of the determination of the fatigue characteristic domains we could see that neighborhood rough set reduction result is the foundation of determination of fatigue characteristic domains. By using neighborhood rough set theory, we don't depend on any prior knowledge to achieve the classification of the welded joint fatigue samples. Each 
class of welded joint fatigue test samples forms a relatively independent sample space, which is called fatigue characteristic domain. S-N curve cluster could be obtained by fitting the S-N curve in each fatigue characteristic domain. The fatigue life of welded joints is evaluated based on the fitted S-N curve cluster, which can further reduce the dispersion degree of fatigue test samples and improve the prediction accuracy of fatigue life of welded joints.

It could be seen from Fig. 11, under semi-log coordination, fatigue test samples of aluminum alloy welded joints with different types of materials, under different stress ratio distributed in a relatively independent space, which is called the fatigue characteristic domain. S-N curve cluster is obtained by fitting the $\mathrm{S}-\mathrm{N}$ curve in each fatigue characteristic domain, Mean $_{1} \sim$ Mean $_{8}$. From Tab.10 and Tab. 11, we could find that SSE and RMSE of Mean7 and Mean 8 are both smaller than that of the Mean, while R-square and Adjusted R-square of Mean $\mathrm{n}_{7}$ and Mean 8 are both closer to 1 than that of the Mean. Smaller SSE and RMSE, bigger R-square and Adjusted R-squares indicate that $\mathrm{S}-\mathrm{N}$ curves fitted based on the characteristic domain have better performance and higher prediction accuracy.

Case study

To further verify the effectiveness of the fatigue life prediction method based on the fatigue characteristics domain, under the same experiment conditions, take one 5A06+5A06 T-joint specimen as example. The three-point bending fatigue test of the welded joint is carried out. Fatigue life prediction of the T-joint by using master S-N curve is compared with the prediction value by using S-N curve Mean ${ }_{8}$ based on the fatigue characteristic domain and the actual value obtained in the fatigue test. The number of cycles to failure of the specimen is 249363 according to Eqn. (10) and it is 516050 by using Eqn. (12). Comparison result show that fatigue life prediction value of the T-joint by using S-N curve Mean 8 is in better agreement with the experiment results than by using the master S-N curve. Actual fatigue life of the test case is shown in Tab. 12.

\begin{tabular}{cccccccc}
\hline $\begin{array}{c}\text { Material } \\
\text { type }\end{array}$ & $\begin{array}{c}\text { Welding } \\
\text { method }\end{array}$ & $\begin{array}{c}\text { Thickness } \\
(\mathrm{mm})\end{array}$ & Ratio & $\begin{array}{c}\text { Loading } \\
\text { type }\end{array}$ & $\begin{array}{c}\text { Joint } \\
\text { type }\end{array}$ & $\begin{array}{c}\text { Equivalent structural stress } \\
\text { range }(M P a)\end{array}$ & $\begin{array}{c}\text { Life } \\
\text { cycles }\end{array}$ \\
\hline $5 \mathrm{~A} 06+5 \mathrm{~A} 06$ & $\mathrm{MIG}$ & 16 & 0.1 & $3 \mathrm{~B}$ & $\mathrm{~T}$ & 113.48 & 775900 \\
\hline
\end{tabular}

Table 12: Fatigue test data of aluminum alloy T-welded joints.

\section{Discussion AND CONCLUSION}

r. hree-point bending fatigue test of aluminum alloy T-welded joint of 5083 and 5A06 is carried out. The finite element model of T-joints is established, and the equivalent structural stress is calculated. The master S-N curve for fatigue design and the S-N curves cluster in different fatigue characteristic domains are fitted according to the experimental fatigue data and the data collected from the literatures. Goodness-of-fit statistics results indicate that the S-N curve cluster has higher prediction accuracy than the master S-N curve. The case study of fatigue life prediction of $5 \mathrm{~A} 06+5 \mathrm{~A} 06$ aluminum alloy $\mathrm{T}$-welded joint specimen show fatigue life prediction by using the $\mathrm{S}-\mathrm{N}$ curves cluster is in better agreement with the experimental results.

Neighborhood rough set theory could find the core factors which influence the fatigue life of the aluminum alloy $\mathrm{T}$ welded joints from the data itself without any prior experience. Fatigue characteristics domain of aluminum alloy Twelded joints could be determined based on reduction results of the neighborhood rough set theory. The result of the case study show that the dispersion level of fatigue samples is further reduced and the fatigue life prediction accuracy is further improved.

Future work will be concentrated on the further validation of the fatigue life prediction method based on the fatigue characteristics domain in the practical engineering.

\section{ACKNOWLEDGEMENTS}

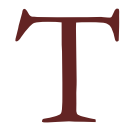
he authors would like to thank all the reviewers for their constructive comments. This research was supported by National Science Foundation of Liaoning Province (2015020169) and Liaoning Provincial Education Department Project(JDL2017025). and the Open Project Program of Sichuan Provincial Key Lab of Process Equipment and Control(GK201815). 


\section{REFERENCES}

[1] Dong, P., Hong J. K., Osage D. et al. (2013). Assessment of Asme's Fsrf Rules for Vessel and Piping Welds using a New Structural Stress Method, Welding in the World, 47, pp. 31-43.DOI:10.1007/BF03266376.

[2] Dong, P. (2001). A structural stress definition and numerical implementation for fatigue analysis of welded joints, International Journal of Fatigue, 23 865-876. DOI:10.1016/S0142-1123(01)00055-X.

[3] Dong, P. and Hong J. K. (2013). The Master S-N Curve Approach to Fatigue of Piping and Vessel Welds, Welding in the World, 48, pp. 28-36. DOI:10.1007/BF03266411.

[4] Guo, H. G., Zhang, J., Zhang, Y. et al. (2013). Structural Stress Based Fatigue Analysis Method for Plane Steel Gate, Advanced Materials Research, 838-841, pp. 314-318. DOI:10.4028/www.scientific.net/AMR.838-841.314.

[5] Hong, J. K. and Cox, A. (2017). Application of Weld Fatigue Evaluation Procedure for Considering Multi-Axial Stress States Using the Battelle Structural Stress Method, proceedings of the SAE World Congress Experience, WCX ${ }^{\mathrm{TM}}$ 17: SAE World Congress Experience. DOI:10.4271/2017-01-0338.

[6] Yaghoubshahi, M., Alinia, M. M. and Milani, A. S. (2017). Master S-N curve approach to fatigue prediction of breathing web panels, Journal of Constructional Steel Research, 128, pp.789-799. DOI: 10.1016/j.jcsr.2016.10.015.

[7] Jain, A., Paepegem, W. V., Verpoest, I. and Lomov, S. V. (2016). A feasibility study of the Master SN curve approach for short fiber reinforced composites, International Journal of Fatigue, 91, pp. 264-274.

DOI:10.1016/j.ijfatigue.2016.06.015.

[8] Dong, P., Prager, M. and Osage, D. (2013). The Design Master S-N Curve in ASME Div 2 Rewrite and its Validations, Welding in the World, 51, pp. 53-63. DOI: 10.1007/BF03266573.

[9] Pawlak, Z. (1984). Rough classification, International Journal of Man-Machine Studies, 51, pp. 469-483.

DOI:10.1006/ijhc.1983.0315.

[10] Wen, L. Y., Min, F. and Wang, S. Y. (2017). A two-stage discretization algorithm based on information entropy, Applied Intelligence, 47, pp. 1-17. DOI:10.1007/s10489-017-0941-0.

[11]Luo, J., Xue, Q. and Tang, Z. W. (2013). Research on Attribute Discretization for Combat Simulation Data, Computer Simulation, 30, pp. 26-13. (in Chinese)

[12] Feng, T., Fan, H. T. and Mi, J. S. (2017). Uncertainty and reduction of variable precision multigranulation fuzzy rough sets based on three-way decisions, International Journal of Approximate Reasoning, 85, pp. 36-58.

DOI: $10.1016 /$ j.ijar.2017.03.002.

[13] Feng, T. and Mi, J. S. (2016). Variable precision multigranulation decision-theoretic fuzzy rough sets, KnowledgeBased Systems, 91, pp. 93-101. DOI:10.1016/j.knosys.2015.10.007.

[14] Rahimi, A., Benini, L. and Gupta, R. K. (2017). From Variability Tolerance to Approximate Computing in Parallel Integrated Architectures and Accelerators, Springer, Switzerland.

[15] Kiapour, A., Naghizadeh and Qomi M. (2017), An Approximate Tolerance Interval for the Size-Biased PoissonLindley Random Variable, 10, pp. 299-316. DOI:10.18869/acadpub.jss.10.2.299.

[16] Tripathy, B. K. and Parida, S. K. (2017). Covering Based Pessimistic Multigranular Approximate Rough Equivalences and Approximate Reasoning, First International Conference on SCI 2016. DOI: $10.1007 / 978-981-10-5544-7 \_30$.

[17] Lin, G. and Li, J. (2011). A Covering-Based Pessimistic Multigranulation Rough Set. 7th international conference on intelligent computing, pp. 673-680. DOI: 10.1007/978-3-642-24553-4_89.

[18]Zhang, J., Li T., Da R. and Liu D. (2012). Neighborhood rough sets for dynamic data mining, International Journal of Intelligent Systems, 27, pp. 317-342. DOI:10.1002/int.21523.

[19] Shakiba, A. and Hooshmandasl, M. R. (2015). Neighborhood system S -approximation spaces and applications, Knowledge \& Information Systems, 49, pp. 749-794. DOI:10.1007/s10115-015-0913-9.

[20] Hu, Q., Yu D., Liu J. and Wu C. (2008). Neighborhood rough set based heterogeneous feature subset selection, Information Sciences, 178(18), pp. 3577-3594. DOI:10.1016/j.ins.2008.05.024.

[21]Dong, P., Osage, D. A., Prager, M. (2002). Master S-N curve method for fatigue evaluation of welded components, Welding Research Council Bulletin, 47, pp. 41-44.

[22] Cruz, J. A. M. P. D., Costa, J. D. M., Borrego, L. F. P. and Ferreira J. A. M. (2000). Fatigue life prediction in AlMgSi1 lap joint weldments, International Journal of Fatigue, 22, pp. 601-610. DOI:10.1016/S01421123(00)00023-2.

[23] Beretta, S. and Sala, G. (2004). A model for fatigue strength of welded lap joints, Fatigue \& Fracture of Engineering Materials \& Structures, 28, pp. 257-264. DOI:10.1111/j.1460-2695.2004.00849. 
[24] Sidhom, N., Laamouri, A., Fathallah, R., Braham, C. and Lieurade, H. P. (2005). Fatigue strength improvement of 5083 H11 Al-alloy T-welded joints by shot peening: experimental characterization and predictive approach, International Journal of Fatigue, 27, pp. 729-745. DOI:10.1016/j.ijfatigue.2005.02.00.

[25] Sidhom, N., Braham, C. and Lieurade, H. P. (2007). Fatigue Life Evaluation of Shot Peened Al-Alloys 5083 H11 T-Welded Joints by Experimental and Numerical Approaches, Welding in the World, 51, pp. 50-57. DOI:10.1007/BF03266548.

[26]Zou, L., Yang, X., Tan, J. et al. (2017). S-N curve modeling method of Aluminum alloy welded joints based on the fatigue characteristics domain, Frattura ed Integrità Strutturale, 40, pp. 137-148. DOI:10.3221/IGF-ESIS.40.12. 